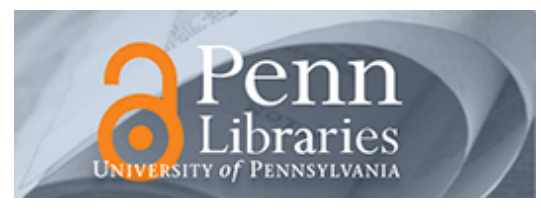

University of Pennsylvania

ScholarlyCommons

Marketing Papers

Wharton Faculty Research

8-2007

\title{
Immediate and Delayed Emotional Consequences of Indulgence: The Moderating Influence of Personality Type on Mixed Emotions
}

Suresh Ramanathan

Patti Williams

University of Pennsylvania

Follow this and additional works at: https://repository.upenn.edu/marketing_papers

Part of the Cognition and Perception Commons, Cognitive Psychology Commons, Marketing Commons, and the Social Psychology Commons

\section{Recommended Citation}

Ramanathan, S., \& Williams, P. (2007). Immediate and Delayed Emotional Consequences of Indulgence: The Moderating Influence of Personality Type on Mixed Emotions. Journal of Consumer Research, 34 (2), 212-223. http://dx.doi.org/10.1086/519149

This paper is posted at ScholarlyCommons. https://repository.upenn.edu/marketing_papers/299

For more information, please contact repository@pobox.upenn.edu. 


\title{
Immediate and Delayed Emotional Consequences of Indulgence: The Moderating Influence of Personality Type on Mixed Emotions
}

\author{
Abstract \\ The majority of literature looking at self-control dilemmas has focused on short-term positive and long- \\ term negative affective outcomes arising from indulgence. In two studies, we find evidence for more \\ complex emotional responses after indulgent consumption. We show that consumers feel simultaneous \\ mixtures of both positive and negative emotions in response to indulgences and that the specific \\ components of those emotional mixtures vary, depending on differences in individual impulsivity. Further, \\ these mixtures are resolved differently over time, leading to differences in subsequent choices. In addition \\ we show that more prudent consumers are likely to seize an opportunity to get rid of, or "launder," their \\ negative emotions after an indulgence by subsequently making utilitarian versus hedonic choices.

\section{Keywords} \\ compulsive/impulsive consumption, affect/emotions/mood, personality, motivation/desires/goals, \\ experimental design and analysis (ANOVA), observation

\section{Disciplines} \\ Business | Cognition and Perception | Cognitive Psychology | Marketing | Social Psychology
}


Immediate and Delayed Emotional Consequences of Indulgence: The Moderating Influence of Personality Type on Mixed Emotions

\section{SURESH RAMANATHAN}

\section{PATTI WILLIAMS*}

forthcoming, Journal of Consumer Research 
*Suresh Ramanathan is assistant professor of marketing at the University of Chicago Graduate

School of Business, 5807 S. Woodlawn Ave, Chicago, IL 60637 (sramana1@gsb.uchicago.edu).

Patti Williams is the James G. Campbell Jr. Memorial Term Assistant Professor of Marketing at The Wharton School, University of Pennsylvania, Philadelphia, PA 19104-6340

(pattiw@wharton.upenn.edu). Both authors contributed equally to this article. The authors thank Young Lee for his assistance with web-programming. We also thank Loraine Lau-Gesk, Mary

Frances Luce, Andrea Morales and Ann McGill for their comments on previous versions of this manuscript, as well as seminar participants at the Northwestern Marketing Camp and at the University of Southern California and UCLA. Finally, the authors thank Dawn Iacobucci, John Deighton, the associate editor and three anonymous reviewers for their invaluable feedback and comments during the review process. 
The majority of literature looking at self-control dilemmas has focused on short-term positive and long-term negative affective outcomes arising from indulgence. In two studies, we find evidence for more complex emotional responses after indulgent consumption. We show that consumers feel simultaneous mixtures of both positive and negative emotions in response to indulgences and that the specific components of those emotional mixtures vary depending on differences in individual impulsivity. Further, these mixtures are resolved differently over time, leading to differences in subsequent choices. In addition we show that more prudent consumers are likely to seize an opportunity to get rid of, or "launder," their negative emotions after an indulgence by subsequently making utilitarian versus hedonic choices. 
Many of us experience a tinge of regret or stress even as we delight in feelings of pleasure from our favorite indulgences, like splurging on an expensive dinner or dipping into the cookie jar. We make resolutions to ourselves that we won’t consume so impulsively or we promise ourselves that this will be the last time, positively. Several studies have documented that such feelings result from impulsive consumption (e.g., Rook 1987; O’Guinn and Faber 1989). Yet, in spite of such ambivalence towards temptations and well-meaning resolutions not to succumb again, consumers often end up repeating the same or similar choices. A substantial amount of consumption is indulgent, as the increasing prevalence of binge drinking (Weschler et al. 2002), obesity (Flegal et al. 2002), and credit card debt (Futrelle 2006) across the country underscores. Moreover, these indulgent acts can have serious negative consequences for individual consumers and for society at large.

A substantial academic literature has examined the emotional consequences of selfcontrol lapses, but has focused almost exclusively on the experience of negative emotions such as guilt and regret after indulgence, and the limiting tendencies that such emotions can have on further indulgence, broadly construed. If, in fact, consumers do experience regret or guilt over their indulgent choices, how is it that they often continue to act in the same manner over time? If regret is experienced after consuming indulgences, surely this negative affect associated with the act should diminish any likelihood of further indulgence and instead prompt a conscious consideration of the costs of one's choices? In this article we focus on the affective phenomenology of indulgent consumption, as it unfolds over time. This experiential view shows that guilt and regret represent only two of the many emotions consumers might feel in response to indulgent choices. In an examination of impulsive indulgent behaviors, Rook $(1987,191)$ noted that they were "hedonically complex," and capable of stimulating "emotional conflict." 
Despite these findings, there remains limited understanding of the complexity of emotions arising from indulgent consumption. We believe that complexity in emotional experience is likely to be a uniquely important aspect of impulsive consumption. Consumption experiences almost always involve multiple, conflicting attributes and goals (e.g., nutrition versus taste for food items; party today versus study for tomorrow's test for campus drinking) and hence the propensity for the consumer to feel the pull of multiple, valid considerations during and after the consumption experience. In this way, impulsive consumption stands in contrast to some other contexts for impulsivity (e.g., anger mis-management or addictive behaviors) which seem to follow from a simple failure to control a momentary urge.

In this article, we develop a more complete understanding of the emotional reactions to indulgent consumption, the dynamics of these emotions over time and the potential impact that such emotions have on subsequent choices. To investigate this domain, we embed our study of emotions within indulgent consumption experiences, and bring together previous research on emotional accessibility and the emotional ambivalence to understand the dynamics of emotional outcomes after acting indulgently. We take a nuanced view of ambivalence, arguing that there are different components of emotional conflict. We examine individual differences in such outcomes, exploring how impulsive personality traits impact emotional responses to indulgent choices and examining the influence of time on such emotions and on subsequent indulgent actions.

\section{THE EMOTIONAL CONSEQUENCES OF INDULGENCE}


A considerable body of literature in psychology and consumer behavior has examined losses of self-control that lead to indulgent behaviors. The general view emerging from this research is that indulgent behavior is characterized by time-inconsistent preferences, or a tendency to overweigh short-term rewards relative to more distant ones and a tendency in the short-term to ignore the costs of one's actions (Ainslie 1975; Prelec and Loewenstein 1991; Thaler and Shefrin 1981). Consumers are seen as easily tempted by choices that promise immediate pleasure and therefore act indulgently, despite long-term interests to avoid such behaviors. Central to this literature is the view that these myopic indulgences are ultimately seen as less legitimate and suboptimal compared to more farsighted goals to abstain (Hoch and Loewenstein 1991). As a result, indulgences are thought to lead to remorse and negative emotions such as regret, guilt, shame or embarrassment. These negative feelings in turn cause a reversal of preferences, consistent now with long-term goals, prompting consumers to wish they had behaved more responsibly (Kivetz and Keinan 2005). The psychological pain associated with these negative emotions is believed to be a primary driver of future self-control. Such pain makes salient the costs of satisfying myopic desires and motivates consumers to give up the pleasure associated with indulgence in deference to their long-term goals (Hoch and Loewenstein 1991).

Focusing in on the emotional consequences of indulgences, this literature suggests that succumbing to indulgence leads to positive affective outcomes in the short-term, but negative affect in the long-term. In his phenomenological study of impulsive behaviors, however, Rook (1987) described considerably more complex emotional outcomes of indulgence, which point to a more dynamic interplay between feeling good and feeling bad. His respondents suggested that 
their impulses provoked simultaneous pleasure and pain, making them feel good, happy and wonderful, and at the same time, panicked, distressed and nervous (p. 195).

This simultaneous occurrence of positive and negative affect in response to indulgences is consistent with recent literature examining attitudinal and emotional ambivalence (Thompson, Zanna, and Griffin 1995; Priester and Petty 2001; Williams and Aaker 2002). This perspective argues that affective valence is represented by two independent dimensions, rather than a single bipolar continuum (Cacioppo, Gardner, and Berntson 1997). The presence of two separate dimensions suggests that consumers need not feel either good or bad, but rather may sometimes simultaneously feel both good and bad. In this article, we contend that the interplay between positive and negative emotional outcomes is more complex than previous literature would suggest. Specifically, we believe that consumers will feel mixed emotions after indulging. However, we expect the specific conflicting emotions to vary across individuals due to differences in underlying traits of impulsivity versus prudence. Further, we expect that the differences in mixed emotional reactions to indulgence will lead to differences in subsequent, post-indulgence, choices.

Considerable work has examined impulsivity as a personality trait or characteristic. Gray (1987) concluded that impulsiveness is driven by an overactive tendency to seek pleasure and an under-active inhibition system. Impulsivity has also been linked to specific personality types such as extraversion, which underlies the tendency to seek excitement or novelty and avoid boredom or monotony (Cloninger, Przybeck, and Svrakic 1991). Prudence (low levels of impulsivity) is associated with high levels of conscientiousness/neuroticism, which underlies constraint and will-power (Tellegen 1982). Several scales have been developed to measure trait impulsivity in individuals (e.g., Puri 1996; Rook and Fisher 1995). Recent work suggests that 
impulsive people are different from prudent individuals not just in their traits, but in their possession of chronic hedonic goal states, which drive people to seek pleasure and hence motivate indulgence (Ramanathan and Menon 2006). This perspective suggests that even those with more prudent traits can activate temporary hedonic goals, causing them to indulge, though this activation wears off with time, leading to a reassertion of self-control goals. We suggest that trait or goal-related differences in the propensity to indulge will also lead to differences in the emotional responses to such indulgences. Further we expect that individual differences with respect to impulsivity will impact how these emotions unfold over time, and that such differences in emotional outcomes will drive subsequent choices. Specifically, we expect the temporal course of indulgence-induced emotional ambivalence to differ for people high and low in impulsivity, further leading to differences in subsequent actions across these groups.

We turn next to a discussion of the specific types of positive and negative emotional responses that may arise after indulgence and how such reactions may vary across individuals.

The Accessibility of Hedonic and Self-conscious Emotions Immediately and Over Time

A number of authors have made a distinction between spontaneous affective processes and higher-order affective reactions that result from more controlled cognitive reasoning (e.g., LeDoux 1996; Pham et al. 2001). Similarly, in his investigation of the attitudes toward selfcontrol dilemmas, Giner-Sorolla (2001) distinguished hedonic from self-conscious emotions. Hedonic affect is immediate and arises quickly and automatically, due to a heightened accessibility of such emotions because of a longer developmental history of experience. Selfconscious affect, in contrast, is more deliberative and slow, arises from more effortful, thoughtful 
processing over time, may be evoked less reliably and develops later in terms of emotional maturation. Emotions of each type can be characterized by valence (positive or negative) and by intensity (LeDoux 1996). Thus in the hedonic domain, one could feel positive emotions such as pleasure and delight, as well as negative emotions such as stress and frustration. Similarly one might feel positive self-conscious emotions such as pride, as well as negative emotions such as guilt and regret (Giner-Sorolla 2001). We use this distinction between hedonic and selfconscious emotions to assess the affective consequences of succumbing to indulgence among impulsive and prudent consumers, both immediately and over time, but argue that there may be differences in how quickly these emotions arise and in how they are resolved.

Immediate Emotional Consequences of Indulgence. Due to differences in the accessibility of spontaneous (hedonic) versus more cognitive (self-conscious) emotions, we expect both prudent and impulsive consumers to report substantial levels of hedonic emotions immediately after indulging (Giner-Sorolla 2001). However, unlike past work on self-control which suggests that consumers will feel only positive hedonic emotions (e.g., pleasure) in the short-term, we argue that consumers will feel both positive and negative hedonic emotions immediately in response to indulgent acts. This is consistent with perspectives that emotionally ambivalent experiences are frequent and may be particularly so in the domain of indulgences (Larsen, McGraw, and Cacioppo 2001; Rook 1987; Kivetz and Simonson 2002). Thus, in addition to feelings of pleasure, one might also feel frustrated for having succumbed to a temptation.

Our expectations with respect to self-conscious emotions are somewhat different, however. First, we do not expect consumers to feel mixtures of positive and negative selfconscious affect after an indulgence. Such acts are likely to lower feelings of pride or self-respect 
(Wood, Quinn, and Kashy 2002), and thus unlikely to provoke positive self-conscious emotions at all. Consistent with past literature on self-control lapses, we expect consumers' self-conscious emotions after indulgence to be primarily negative (e.g., guilt and regret). However, unlike past literature which has focused on the emergence of regret over the long-term, we expect such negative self-conscious emotions could also emerge very quickly, leading to further simultaneous mixing of positive and negative emotions.

While self-conscious emotions are usually less immediate than hedonic emotions, they might become more accessible if people are vigilant towards the experience of such emotions. Recent research suggests that those with prudent personality traits (e.g., scoring high on neuroticism or anxiety scales) may be more likely to experience guilt or regret when they do indulge because they are susceptible to the negative emotions associated with the action (Canli et al. 2001). Over time, their strong and consistent experience of such emotions may result in a degree of automaticity or routinization of these emotions, causing them to be incorporated into their immediate reactions to indulgences (Giner-Sorolla 2001). Thus, we expect that selfconscious emotions will be more accessible and felt immediately among those with a higher level of self-control. In contrast, we expect that self-conscious emotions are unlikely to be accessible immediately to individuals who are more impulsive (more extraverted) as they are dispositionally less sensitive or receptive to negative affect (Canli et al. 2001). Thus, they are unlikely to have routinized these more effortful negative feelings into their immediate reactions.

Delayed Emotional Consequences of Indulgence. Recent work suggests that there is a significant amount of intra-individual variability in affect over time that can be predicted by personality traits like extraversion or neuroticism and by goal orientations such as approach or 
avoidance (Diener and Larsen 1984; Eid and Diener 1999). Those with strong approach or reward-seeking motivations (impulsives) appear likely to experience more positive emotions over time, and also to systematically devalue or pay less attention to negative emotions over time (Updegraff, Gable, and Taylor 2004). Those with strong avoidance motivations (prudents), on the other hand, pay more attention to negative emotions, which therefore persist over time. Consistent with these results, we expect that indulgence will lead to differences in positive and negative emotional reactions over time across individuals who are more or less impulsive. Thus, we expect that among those who are more impulsive, positive hedonic emotions will linger while their negative emotional reactions will decline. In contrast, we expect that among those who are prudent, negative emotions—both hedonic and self-conscious—will linger, while more positive emotions will decline with time.

The Impact of Indulgence-Related Emotions on Subsequent Choice

As described above, much of the literature on self-control has focused on the impact of emotions such as regret on subsequent self-controlling actions (Gilovich and Medvec 1994; Tsiros and Mittal 1998). This research suggests that experience with regret makes the pain of indulgent choices more salient, and increases consumer motivation for self-control, reducing the likelihood of future indulgence. As such, we expect that immediate and delayed emotional responses to acts of indulgence will impact subsequent intentions to engage in additional indulgence. While both impulsive and prudent individuals are expected to experience ambivalence immediately after acting impulsively, the greater attention to positive emotions among impulsives should lead to relatively higher intentions for them to repeat the behavior 
compared to prudent individuals. With delay, the emotional responses of prudent individuals are expected to be predominantly negative, resulting in lower intentions to indulge a second time. However, the emotional responses of impulsive individuals are expected to become more positive over time, increasing the likelihood they will succumb to indulgence a second time.

Undoing Ambivalence: Laundering Negative Emotions

Previous literature has suggested a number of ways that consumers might cope with emotional conflict, such as engaging in problem-focused coping to change the situation they find themselves in, or in emotion-focused coping such as engaging in avoidance strategies or in reinterpretations of their situations (Lazarus 1991; Luce 1998). Some research has suggested that emotionally conflicted consumers might make utilitarian (versus hedonic) consumption choices in order to undo, or “launder," negative emotions arising in a consumption setting (Levav and McGraw 2004). This process is thought to be similar to "moral cleansing” (Tetlock et al. 2000), whereby individuals engage in virtuous behaviors to reduce negative feelings arising from socalled "taboo" trade-offs which inappropriately extend market-pricing to sacred spheres (such as buying and selling human body parts for medical transplant operations). These trade-offs create a sense of outrage and contamination and a desire to restore moral order through actions. The path from taboo tradeoff to moral outrage to moral cleansing is especially strong among those whose beliefs have been most directly challenged by the tradeoff (Tetlock et al. 2000).

Because prudent consumers are likely to be especially attuned to their negative emotional reactions to indulgence, we expect that they are also more likely to seize an opportunity to launder these negative emotions. When prudent individuals have an opportunity to make a 
utilitarian (versus hedonic) choice after once acting indulgently, we expect they will be very likely to do so, compared with more impulsive consumers. Similar to the moral cleansing effects, the utilitarian choice will help reduce the negative emotions experienced in response to their indulgence and restore their own sense of themselves as prudent, a conception which has likely been strongly challenged after a lack of self-control. On the other hand, impulsive consumers, are likely to be more comfortable with their ambivalence, buttressed by their focus on the positive emotions arising from the indulgence, leading us to expect they will be less likely to undertake any laundering actions. Table 1 details our predictions for emotional reactions and subsequent choices in both experiments.

Insert table 1 about here

Experiment 1 examines the emotions that arise after engaging in indulgences, their course over time, and their impact on subsequent choices among prudent and more impulsive consumers. Relying on a different operationalization of impulsivity, Experiment 2 replicates many of the results of experiment 1 , but focuses primarily on the potential for consumers to launder the negative emotions they feel after being indulgent.

\section{EXPERIMENT 1}

Experiment 1 is a 2 (Personality Type: Impulsive v. Prudent) X 2 (Timing of Second Choice Measurement: Immediate v. Delay) between subjects design. All delayed measures took place within 24-48 hours after the first portion of the experiment. 
Method

Participants and Procedure. The experiment was completed by 158 undergraduates (45\% female; median age = 20 years), in groups ranging in size from two to five individuals, in return for partial course credit. Participants began the experiment as soon as they entered the room, so that a natural staggering of completion times occurred. Participants first completed a nine-item questionnaire measuring impulsivity in shopping as a personality trait, validated by Rook and Fisher 1995 (1. I often buy things spontaneously; 2. "Just do it” describes the way I buy things; 3. I often buy things without thinking; 4. "I see it, I buy it" describes me; 5. "Buy now, think about it later” describes me; 6. Sometimes I feel like buying things on the spur of the moment; 7. I buy things according to how I feel at the moment; 8. I carefully plan most of my purchase; 9. Sometimes I am a bit reckless about what I buy.) To reduce any demand effects after the scale completion, they then completed a variety of unrelated experimental tasks, which filled approximately 30 minutes. Next, they completed a scrambled sentence task designed to prime a hedonic goal (Chartrand and Bargh 1996). Participants were given 20 sets of five words each and asked to make sentences using four of the five words. Eight of the items included a word (italicized in the samples below) intended to prime a hedonic goal (e.g., it herself completely indulged she; ate she it delicious all; drink this look seems tempting; yummy the tastes food hot). Participants were then told that they would complete a personality questionnaire which previous research had found was more accurate when respondents answered it alone rather than with others.

A lab assistant then directed participants, one at a time, into a separate second room equipped with a one-way mirror. Care was taken so that no participant waited more than five 
minutes before entering this second room, in order to prevent a reduction in the priming of the hedonic goal. In fact most participants did not wait at all, due to the small groups in which the study was conducted and the natural staggering of completion times across individuals. Participants were asked to complete a one-page, fictional personality assessment. In the center of the table at which they were seated was a platter of a variety of large cookies. The assistant was coached to say off-handedly to the respondents, "We had a departmental meeting a little while ago and I just brought these cookies over from there.” No explicit invitation to take or to not take a cookie was made in order to avoid demand effects. Unknown to participants, a second lab assistant observing through the one-way mirror noted whether or not each participant chose to take a cookie, and if so how many.

Participants returned to their original seats and were randomly assigned to either the immediate or delayed condition by a web-based questionnaire. Each participant provided an email address they would check approximately 24 hours later. Those in the immediate condition then completed the questions, asking how they felt about their decision to take or not to take a cookie in the other room in response to a list of emotional items. Afterwards, they were presented with a web-page showing eight photographs of hedonic food items (e.g., cheesecake, ice cream, etc.) and asked how likely they would be at that moment to take one of the items presented. All participants received an email from the experimenters 24 hours after completing the laboratory-based portion of the experiment. Those in the immediate condition were thanked and told they had completed the study. Those in the delayed condition were given a link to the emotional response and choice items, which they then completed.

Results 
Impulsivity versus Prudence. Based upon a median split of the responses to the personality scale ( $\alpha=.94$; Median $=4.25$ ), 85 participants were classified as impulsive and 73 as prudent.

Indulgent Cookie Choice. A 2 X 2 logistic regression was performed on cookie choice (as reported by the lab assistant). Results show a significant main effect of personality type $\left(\chi^{2}(1, \mathrm{~N}\right.$ $=158)=115.43, p<.001)$, with a greater percentage of impulsives (95\%) taking a cookie relative to prudent consumers (33\%). No other effects were significant ( $p$ 's > .17). A 2 X 2 ANOVA performed on the number of cookies taken show a significant main effect of personality $(F(1,157)=54.50, p<.0001)$, such that impulsives took an average of 1.39 cookies while prudents took an average of .44 cookies. No other effects were significant ( $p$ 's $>.26$ ).

Emotional Responses to Indulgence. Participants were asked to indicate the degree to which they experienced a variety of emotions in response to their decision to take or not take a cookie in the second room (where $1=$ not at all and 7 = very much; positive hedonic items: fun, excited, relaxed, pleased, satisfied, happy ( $\alpha=.90$ ); negative hedonic items: depressed, stressed, disgusted, angry, frustrated ( $\alpha=.88)$; positive self-conscious items: proud, confident, selfrespectful ( $\alpha=.89)$; negative self-conscious items: guilty, ashamed, regretful $(\alpha=.95)$ ). All items were drawn from Giner-Sorolla (2001) and Williams and Aaker (2002). Emotional responses to indulgence are based upon a total of 105 participants who took a cookie. We examined the valence of emotional responses within each type of emotion (hedonic and self- 
conscious) over time. Table 2 shows the results obtained for emotional responses and the likelihood to indulge again.

Hedonic Emotional Responses to Indulgence. A 2 X 2 ANOVA on positive hedonic emotions found significant main effects of both personality type $(F(1,104)=39.72, p<.0001)$ and of timing $(F(1,104)=76.37, p<.0001)$. More importantly, however, there was a significant interaction between impulsivity and timing $(F(1,104)=33.18, p<.0001)$, as expected. Contrasts showed both impulsive $(M=4.96)$ and prudent $(M=4.86)$ participants felt substantial positive hedonic emotions immediately after indulging. Over time both impulsive $(M=4.42$ and prudent $(M=2.23)$ participants felt less positive hedonic emotions (contrast with immediate means $p$ 's < .01), however impulsives felt significantly more positive hedonic emotions than prudents $(F(1$, 104) $=67.46, p<.0001)$, as expected.

\section{Insert table 2 about here}

A 2 X 2 ANOVA on negative hedonic emotions found a significant main effect of impulsivity $(F(1,104)=106.02, p<.0001)$, but more importantly also a significant interaction between impulsivity and timing $(F(1,104)=61.39, p<.0001)$, as anticipated. Both prudent $(M=$ 5.14) and impulsive $(M=4.72)$ consumers felt negative hedonic emotions immediately after indulging, with a marginal difference in their levels $(F(1,104)=3.29, p<.07)$. However, there was a significant difference in the amount of negative hedonic emotion felt by prudent $(M=$ 5.21) versus impulsive $(M=2.09)$ consumers with a delay. Over time, there was a significant decline in negative hedonic emotions among impulsive consumers $(F(1,104)=255.21, p<$ 
.0001). Prudent consumers, in contrast, continued to feel similar high levels of negative hedonic emotions over time $(F<1)$.

Thus, both impulsive and prudent participants felt mixed positive and negative hedonic emotions strongly and equally immediately after an indulgence. Over time, however, the mixed hedonic responses were resolved differently for the two groups. Impulsives continued to feel positive but not negative hedonic emotions over time, while prudents continued to feel negative, but not positive hedonic emotions with delay. Together, this supports our expectations with respect to hedonic emotions.

Self-Conscious Emotional Responses to Indulgence. As expected, participants reported feeling relatively low levels of positive self-conscious emotions after indulgence, either immediately or with delay, and a 2 X 2 ANOVA found no significant effects (all p's > .28). There were differences, as expected, however on negative self-conscious emotions. A 2 X 2 ANOVA on negative self-conscious emotions found a significant main effect of impulsivity $(F(1,104)=71.25, p<.0001)$ and of timing $(F(1,104)=16.30, p<.0001)$. Consistent with our expectations, there was also a significant interaction between impulsivity and timing $(F(1,104)=$ 4.01, $p<.05)$. Contrasts showed that while impulsive consumers felt more negative selfconscious affect over time $\left(M_{\text {immediate }}=1.63 M_{\text {delay }}=2.89 ; F(1,104)=40.01, p<.0001\right)$, with a delay they nonetheless felt less negative self-conscious affect than did prudent participants $(M=$ 5.61; $F(1,104)=77.50, p<.0001)$. Prudent participants, however, felt negative self-conscious affect strongly and equally both immediately $(M=5.17)$ and with delay $(F(1,104)=1.34, p=$ .25). As expected, we find that prudent participants feel mixed hedonic and also negative selfconscious emotions immediately. Over time, however, they are left only with negative emotional 
responses to an act of indulgence. In contrast, impulsives feel mixed hedonic emotions immediately, feel little guilt or regret over their indulgence at all, and over time feel only positive emotions.

Likelihood to Indulge a Second Time. Finally, we examined the degree to which respondents would indulge a second time, as measured by their likelihood to choose a hedonic food item shown in photos (cheesecake, ice cream, etc.). A 2 X 2 ANOVA on expressed intent revealed a significant main effect of personality type $(F(1,104)=21.81, p<.0001)$. Again, however, there was a significant interaction between impulsivity and timing $(F(1,104)=15.81$, $p<.0001)$. Consistent with expectations, impulsive consumers reported a greater likelihood to be indulgent again with delay $(M=6.51)$ relative to immediately $(M=5.29, F(1,104)=6.51, p<$ .01). In contrast, however, over time prudent people were less likely to indulge a second time $\left(M_{\text {delay }}=2.54\right.$ v. $\left.M_{\text {immediate }}=5.08 ; F(1,104)=9.86, p<.01\right)$. As expected, impulsive consumers expressed a higher intention to indulge a second time with delay than did prudent consumers $(F(1,104)=16.26, p<.0001)$. However, there was no such difference immediately after the first indulgence $(F<1)$, when both impulsive and prudent individuals expressed similar high intentions to indulge a second time, despite the fact that the prudents experienced higher levels of negative self-conscious emotions.

Mediation. A mediation analysis was done to examine the degree to which these expressed intentions to make a second hedonic choice was predicted by experienced emotions over time (Baron and Kenny 1986). To do so, we created a single index of emotional responses whereby the combined hedonic and self-conscious negative emotional responses were subtracted 
from the combined hedonic and self-conscious positive emotional responses. Results show that the interaction between personality type and timing predicts both total emotional responses $(t(1$, $104)=-7.02, p<.0001)$ and subsequent intention to choose $(t(1,104)=-3.11, p<.01)$. In addition, total emotions predicts subsequent choice intent $(t(1,104)=4.55, p<.0001)$. However, when both total emotions and the interaction between personality type and time are included as predictors of the second choice intention, total emotional responses remains significant $(t=$ 10.30, $p<.0001)$, while the interaction is no longer significant $(t<1, p=.42)$. Thus, the interaction effect between personality type and timing on subsequent choices is fully mediated by emotional responses over time to respondents’ first impulsive action.

\section{Discussion}

Experiment 1 demonstrates that impulsive and prudent consumers experience a complex blend of positive and negative emotions immediately in response to indulgences. Impulsive consumers experience both positive and negative hedonic emotions, while prudent consumers experience both positive and negative hedonic emotions, as well as the negative self-conscious emotions of guilt and regret that have been most often explored in the literature on self-control. Thus, while all individuals experience ambivalence, the components of this ambivalence are distinct for impulsive and prudent individuals. Importantly, the results also demonstrate that the time course of these components of emotional ambivalence is also different for impulsive and prudent consumers. Among prudents, positive hedonic affect declines over time, leaving them with predominantly negative responses to indulgences. Among impulsives, however, the 
negative hedonic emotions decline over time (though negative self-conscious emotions increase slightly over time), leaving them with predominantly positive responses to an indulgence.

Finally, we find that these emotional responses over time drive subsequent indulgent choices, though perhaps not quite as we had anticipated. We expected that prudent participants would be guided by their negative self-conscious emotional responses and would thus be less likely to indulge a second time relative to impulsive participants. While we find this to be true with a delay, in the short-term, even the prudent participants express a strong likelihood of future indulgence, despite their high levels of guilt and regret. It seems, then, that prudents are driven not by their negative self-conscious reactions in the short-term, but by their positive hedonic emotions, just as are the impulsives. Our results suggest that the more respondents feel positive emotions in response to a first indulgence, the more likely they are to indulge again a second time, regardless of trait impulsivity. Another explanation for these results could also lie in the debilitating effects of ambivalence or conflict. Work on ego-depletion has shown people often end up losing control after performing tasks that are taxing or involve difficult trade-offs (Vohs and Heatherton 2000), perhaps even the task of coping with emotional ambivalence. Our results, however, indicate that as positive emotions decline in favor of negative hedonic and selfconscious emotions over time due to differences in impulsivity, the likelihood of a second indulgence declines.

It is possible that the results obtained in this experiment are driven by self-selection, as only those who opted to take a cookie are included in our analysis. We took several steps in the experimental setting to eliminate self-selection effects as much as possible. We ran participants in small groups and insured little to no waiting time before entering the second experimental room, to make sure that our hedonic goal manipulation was equally strong across personality 
types. The tray of cookies was replenished after a cookie had been taken. In addition, we hope that our analysis focusing on those who took a cookie rules out the potential effect of selfselection on the affect results, if not upon original cookie choice. In the next study, we use smaller cookies, in the hope that these might entice even prudent participants to be just a little bit bad, minimizing the effects of self-selection on our results, and resulting in more balanced cell sizes..

It is also possible that the higher intention reported by impulsive people in this experiment to pick something hedonic in a second choice is a function of state dependence. In other words, impulsive people, having acted impulsively once, may have just expressed an intention to repeat the same behavior. While the strong negative hedonic emotions reported by impulsive people might argue against this explanation, we address all of these potential selfselection issues in experiment 2. We rely upon a different domain of behavior for the second choice. Further, since the first experiment only measured intentions on a "virtual” second choice, we use a real choice task in the second study. Also, while in this study we explore the idea that choices create emotions which then lead to subsequent choices, in the next study we also look at the degree to which subsequent choices also help “undo” emotions.

Experiment 2 attempts to understand the extent to which impulsive and prudent individuals undertake actions to mitigate their emotional ambivalence after indulgence. Specifically, we examine whether choosing utilitarian options might help people launder the ambivalence they experience in response to a previous indulgence.

\section{EXPERIMENT 2}


Experiment 2 is a repeated measures mixed design. Personality type (Impulsive v. Prudent) and type of second choice (Hedonic v. Utilitarian) are between subjects factors, with time of emotion measurement (After Choice 1 and After Choice 2) repeated within subjects. Participants were randomly assigned to the second choice task conditions.

Method

Participants and Procedure. 135 undergraduates $(47 \%$ female; median age $=20.4)$ completed the experiment in return for partial course credit. To assess personality type, we used a procedure that identifies impulsive and prudent consumers based upon differences in the chronicity of their hedonic goals (Moskowitz et al. 1999; Ramanathan and Menon 2006). In our procedure, we elicited evaluations of 12 hedonic products (including photos of desserts, mp3 players, CDs and snacks such as nachos and chips), forced participants to respond prudently to a set of four different tempting situations, and then re-elicited evaluations of the hedonic products. If respondents possess chronic hedonic goals, this should be reflected in compensatory behavior that leads to in increased liking for hedonic products after forced prudence. If, in contrast, these goals are not chronic, the prudence task should activate constructs related to self-control or prime prudence goals, so that the hedonic products are liked less. Thus, responses to the evaluation task allow us to identify those with or without the chronic pleasure-seeking goals that are characteristic of impulsivity. Note that the task is loaded in favor of a prudent response and hence, if residual demand effects are in play, should lead to reduced incidence of impulsive behavior. Details of the procedure are available from the authors. 
Participants then completed approximately 30-minutes of unrelated experimental tasks, in order to reduce any demand effects after completion of the impulsivity measurement task. They then completed the scrambled sentence task used in experiment 1 designed to prime a hedonic goal. Again, after completing this task, they were told of the second personality task that needed to be completed alone and were directed, individually, into the second room equipped with the one-way mirror, where they could indulge by taking mini-sized cookies from a tray. The same cover story for the cookies was used. As in experiment 1, a second lab assistant stood behind the one-way mirror recording whether each respondent took a cookie, and if so, how many.

Upon leaving the second room participants returned to their original seats and indicated how they felt about their decision to take or not to take a cookie in response to the list of emotional items used in experiment 1 , on an internet-based survey. Next, they completed a short set of unrelated experimental tasks, filling approximately ten minutes. When finished, they proceeded one at a time around a corner (out of sight and hearing of the main laboratory room) to check out with a lab assistant seated at a table, where there were either several small packages of assorted chips or several small, (4 X 6 inches) plain, white notepads, each worth about 50 cents. Participants were randomly assigned to receive either of these two options. The lab assistant was coached to say, “As an additional thank you for your participation, you can choose some chips (a notepad) to take.” The assistant then surreptitiously made note of whether participants chose one of the items, and also asked them to complete one last task before leaving. They were given a one-page questionnaire asking them to again reflect on their decision to take or not to take a cookie and to respond to the same list of emotional items.

Results 
Impulsivity versus Prudence. To assess the degree to which respondents could be classified as either impulsive or prudent, their initial response scores to the 12 hedonic pictures were subtracted from their delayed response scores. Those participants whose overall difference score was positive were deemed to possess chronic hedonic goals and designated as impulsive ( $N$ $=58$ ). Those whose overall difference score was negative were considered to not have chronic hedonic goals and designated as prudent $(N=78)$. Four respondents reported identical scores in round 1 and round 2 of the picture liking task and were eliminated from the dataset.

Indulgent Cookie Choice. A 2 (personality type: impulsive v. prudent) by 2 (second choice type: hedonic v. utilitarian) logistic regression was performed on observed cookie choice as the dependent variable. In addition, covariates measuring self-reported hunger $(1=$ not at all hungry, 7 = very hungry $)$ and liking for cookies ( $1=$ not at all, $7=$ very much $)$ were included. Results show a significant main effect of personality type $\left(\chi^{2}(1, \mathrm{~N}=131)=4.48, p<.03\right)$, with a greater percentage of impulsive respondents (89\%) versus prudent respondents (69\%) choosing to take cookies. In addition, self-reported hunger was a significant covariate $\left(\chi^{2}(1, \mathrm{~N}=131)=\right.$ 18.12, $p<.0001)$. There were no other significant effects $\left(\chi^{2}<1\right)$. An additional 2 X 2 ANCOVA was performed on the observed number of cookies taken as the dependent variable. Results show a significant main effect of personality type $(F(1,130)=17.51, p<.0001)$, such that impulsives took an average of 4.68 cookies, versus 2.50 among prudents. Self-reported hunger $(F(6,130)=3.75, p<.001)$ and like for cookies $(F(6,130)=3.27, p<.01)$ were significant covariates. No other effects were significant ( $p$ 's > .30). 
Chips or Notepad Choice. A 2 X 2 logistic regression examined actions in the second choice task, among those who indulged by taking a cookie $(N=102)$. Results show only a significant interaction between personality type and type of second choice $\left(\chi^{2}(1, \mathrm{~N}=102)=\right.$ $17.27, p<.001$ ). Impulsive consumers were more likely to choose a hedonic product (chips; $M=$ $86 \%$ ) vs. utilitarian product (notepad; $M=50 \%$ ) after having indulged with a cookie. In contrast, prudent consumers were more likely to choose the notepad ( $M=89 \%)$ compared to chips ( $M=$ 38\%) after having indulged with a cookie. Table 3 shows the results obtained for choice of item and the emotional responses at time 1 and time 2.

Insert table 3 about here

Hedonic Emotional Responses to Indulgence. Because we are interested in the impact of a second choice (hedonic or utilitarian) on emotional responses to the original indulgence, these analyses were run only on those consumers who both took a cookie and either chips or a notepad $(N=61)$. A 2 X 2 repeated measures ANCOVA on positive hedonic emotional responses ( $\alpha=$ .81) to indulgence shows no significant effects (Wilks Lambda $p$ 's $>12$ ). All respondents reported feeling substantial positive hedonic emotions in response to an indulgent cookie choice across both time periods (M’s range from 4.70-5.19).

A 2 X 2 repeated measures ANCOVA examining negative hedonic emotional responses $(\alpha=.91)$ after indulgence found a significant interaction between time and personality type (Wilks Lambda $F(1,57)=7.51, p<.01$ ), and between time and type of second choice (Wilks Lambda $F(1,57)=11.51, p<.001)$. Consistent with our predictions, however, these effects were qualified by a significant interaction between personality type, type of second choice and time (Wilks Lambda $F(1,57)=3.81, p<.05$ ). Contrasts showed that prudent consumers report 
significantly lower negative hedonic emotions about their previous indulgence, if they chose to take a notepad (time $1 M=4.60$; time $2 M=1.45(F(1,57)=9.87, p<.01)$ ). In contrast, prudents who took chips showed no such reduction in negative hedonic emotions (time $1 M=$ 4.76; time $2 M=5.18(F<1))$. Among impulsive consumers, negative hedonic emotions remained relatively high and stable across time regardless of type of second choice (chips: time 1 $M=4.77$; time $2 M=5.72(F<1)$; notepads: time $1 M=4.43$; time $2 M=4.41(F<1))$. Thus, prudent consumers who make a utilitarian choice after a previous indulgence seem able to launder their negative hedonic emotions about that indulgence.

Self-Conscious Emotional Responses to Indulgence. A 2 X 2 repeated measures ANCOVA on positive self-conscious emotions $(\alpha=.90)$ showed that participants experienced minimal positive self-conscious emotions in response to a decision to take a cookie, both at time 1 (M's range from 1.50-2.06) and time 2 (M's range from 1.51-2.28; Wilks Lambda Fs <1).

A 2 X 2 repeated measures ANCOVA on negative self-conscious emotions $(\alpha=.95)$ showed a significant main effect of time (Wilks Lambda $(F(1,57)=16.35, p<.001)$, a significant interaction between time and personality type (Wilks Lambda $F(1,57)=23.16, p<$ $.0001)$ and between time and type of second choice (Wilks Lambda $(F(1,57)=11.10, p<.01)$. Again consistent with our expectations about laundering negative emotions, however, these effects were qualified by a significant interaction between personality type, second choice type and time (Wilks Lambda $F(1,57)=19.67, p<.0001)$. Contrasts showed that prudents reported lower negative self-conscious emotions about their previous indulgence after having taken a notepad ((time $1 M=5.10$; time $2 M=1.40(F(1,57)=19.28, p<.0001))$, but not after taking chips (time $1 M=5.21$; time $2 M=4.97(F<1)$ ). Among impulsives, negative self-conscious 
emotions were relatively low and stable across time regardless of type of second choice (chips: time $1 M=1.85$; time $2 M=1.78(F<1)$; notepads: time $1 M=2.22$; time $2 M=2.63(F<1)$ ).

Mediation. In experiment 1, we conducted mediation analyses to understand the impact of emotions on subsequent immediate and delayed choice behavior. For experiment 2, we conducted mediation analysis to understand the impact of the second choice on emotional responses to the previous decision to impulsively take a cookie. To do so, we created two indices of emotional responses (one at time 1 and another at time 2), whereby the combined hedonic and self-conscious negative emotional responses were subtracted from the combined hedonic and self-conscious positive emotional responses, as in experiment 1 . We then subtracted the summed emotional responses at time 2 from the summed responses at time 1 to create a difference score. We examined the impact of the interaction between personality type and the type of second choice (hedonic or utilitarian) on whether or not subjects chose the second item and on the resulting differences in emotions between time 1 and time 2. Results show that the interaction between personality type and timing predicts both subsequent choice of chips or notepads $\left(\chi^{2}(1\right.$, $\mathrm{N}=102)=14.78, p<.0001)$ and the difference between total emotional responses at time 1 and time $2(t(1,101)=-6.64, p<.0001)$. In addition, choice of either notepads or chips predicts the difference in total emotions at time 1 and time $2(t(1,101)=4.02, p<.0001)$. Finally, when both the interaction between personality type and type of second choice offered and whether or not a second choice was made are included as predictors of the difference in emotional responses over time, incidence of second choice is significant $(t(1,101)=5.90, p<.0001)$, as is the interaction between personality type and choice type $(t(1,101)=-8.01, p<.0001)$. Thus, the interaction 
effect between personality type and timing on emotional responses over time is partially mediated by whether or not respondents chose to take either chips or notepads.

\section{Discussion}

Experiment 2 extends our findings, showing not just that people experience various forms of ambivalence immediately after an indulgence, but also that there are differences across individuals in the tendency to reduce that ambivalence via laundering of negative emotions. Thus, when normally prudent consumers who have indulged are given the opportunity to make a utilitarian choice a second time round, they are likely to do so. And, this choice produces a change in their emotional responses to the original indulgence, reducing the negative hedonic and self-conscious emotions they feel about having previously been indulgent.

These results suggest that impulsive people may be better able to cope with duality or ambivalence arising out of their previous indulgent actions. Despite the presence of utilitarian options that might be a potential external means of reducing negative emotions and thus reducing ambivalence, they continue to pursue hedonic choices. Prudent people, however, may seize the opportunity to reduce negative emotions through utilitarian choices because they are less adept at coping with emotional ambivalence arising after indulgence (Williams and Aaker 2002).

\section{GENERAL DISCUSSION}

In two experiments we examine the immediate and delayed emotional consequences of engaging in indulgent consumption among both prudent and impulsive consumers. While past 
work has focused on the experience of regret in response to indulgences, we find evidence of more complex emotional outcomes. Specifically, we find that both groups of consumers experience mixed emotions immediately after consuming a food indulgence. However, the components of that ambivalence are different across the two groups. While impulsive people are ambivalent because of the presence of positive and negative hedonic emotions, prudent people are ambivalent because of the experience of positive and negative hedonic emotions, as well as negative self-conscious emotions. Further, while emotional ambivalence is reduced after a delay for both groups, the source of the reduction is different. Impulsive people continue to feel residual effects of their positive hedonic emotions, but experience a sharp decline in their negative hedonic emotions. Prudent people continue to experience strong negative hedonic and self-conscious emotions, but report significantly lower levels of positive hedonic emotions. This, in turn, affects the propensity to repeat an act of indulgence. Finally, we find differences in the extent to which people take actions to undo their emotional ambivalence. We ascribe these differences to coping mechanisms adopted by the two groups. Impulsive people may be more comfortable with duality or conflict, or may be more resigned to the experience of such conflict. Prudent people, on the other hand, seem to be more eager to seize the chance to launder their negative emotions.

Our findings extend previous research, both on self-control and on ambivalence in several ways. First, unlike previous studies, our data focuses not just on the immediate affective experiences after a single indulgent act, but also addresses the dynamics of these affective reactions and their relative impact on subsequent consumption. Thus, for example, we do not rely on memories of past behaviors or affect (Rook 1987), on response latencies to words pertaining to different forms of affect, or self-reported reactions to hypothetical scenarios (cf. 
Giner-Sorolla 2001). Rather, we trace the time course of affective experience in response to actual consumption. Further, we extend past research by examining not just the incidence of a single impulsive act as is common (Hoch and Loewenstein 1991; Shiv and Fedorikhin 1999), but also the intentions and actual enactment of subsequent behaviors. Prior research on consumption across episodes has shown that consumers attempt to balance the attributes of products consumed, such as having something healthy after consuming something tasty or indulgent (Dhar and Simonson 1999). Our contribution lies in the documentation of how emotional ambivalence after indulgence is experienced immediately and resolved over time and how this varies across individuals, as manifest in their propensity to balance their behavior or launder their emotions. In addition, our findings add to the literature on mixed emotions, suggesting that it is necessary to examine differences in the specific emotions that contribute to the conflict, and how these different components might strengthen or dissipate over time as consumers cope with their ambivalence. Finally, while our focus has been on the topic of mixed emotions, we believe our results offer implications for researchers studying attitude ambivalence as well, as it is likely that ambivalent attitudes and ambivalent emotions often co-occur. Also, previous research has suggested that indulgences may often reflect a struggle to overcome conflicts between heart and mind, or between the affective and cognitive components of attitudes. The present research suggests that such conflict likely exists both across attitudinal components and within those components. Not only might indulgences invoke conflict between heart and mind, but such conflict may exist within the heart as well.

In addition to our theoretical contributions, we offer insights for those interested in the phenomenon of indulgent or impulsive consumption, especially public policy makers and consumers. Our results may imply actions to those interested in curbing consumers' indulgent 
tendencies. The finding that negative self-conscious emotions tend not to occur among those consumers most likely to indulge (impulsive consumers) may suggest interventions that highlight such emotions. Alternatively, knowing that impulsive consumers feel negative hedonic emotions significantly more compared to negative self-conscious emotions immediately after an indulgence suggests it might be easier to highlight emotions of stress and anxiety to reduce the likelihood of subsequent indulgent acts rather than to try and focus on creating guilt or regret.

Further, our results raise an interesting question regarding indulgent tendencies amongst those who might otherwise consider themselves prudent consumers. Specifically, does laundering one’s negative emotions create a license to indulge again, among these more selfcontrolling consumers? Perhaps once a utilitarian choice has been made, thereby reducing the negative emotions associated with a previous indulgence, prudent consumers might actually be more likely to consume indulgently the next time an opportunity presents itself. That is, once the negative emotions have been cleansed, their limiting, self-controlling effects on future behavior might also be reduced, making future hedonism more likely. If so, it would be important to know to what extent consumers naturally make these laundering choices in the real world. Do prudent consumers who have indulged seek out other consumption opportunities to launder the negative emotions that occur after indulgence? Our results suggest they might, and also suggest that even those consumers who think of themselves as prudent may be at more risk to over-indulge than they think. This is exacerbated by the fact that even prudent consumers experience significant positive hedonic emotions immediately after indulging themselves, and express a fairly strong likelihood of repeating such behavior despite feeling negative emotions. If the only thing that holds such consumers back is the power of the negative emotions, there is a greater risk of overindulgence if such consumers figure out means to launder such emotions. 
Marketers, in fact, seem to already be aware of the potential cleansing effects of prudent choices. Subway recently ran a series of ads showing how people could go to absurd lengths to indulge themselves, all the while justifying their actions by saying that it was okay since they had prudently eaten a Subway sandwich for lunch. If successful self-regulators are in fact ones most prone to such acts of licensing, as our findings suggest, marketers could develop targeted promotions that tie indulgences with utilitarian goods. Thus, rather than running a scheme like a "buy one, get one free” for ice-cream (something that is likely to increase feelings of guilt), marketers could offer to contribute an equivalent dollar value of the ice-cream to charity upon purchase of one unit of the ice-cream. This could help people launder their guilt about consumption and facilitate future purchases (Strahilevitz 1999).

While we are interested in the emotional reactions to indulgent consumption, it is important to note that our research limits itself to acts of indulgence specifically within the domain of food and eating. Further, our research is conducted within a controlled laboratory environment and thus is by nature somewhat artificial, and offers limited external validity. It is not clear whether similar patterns of indulgent consumption, emotional outcomes and subsequent choices will be observed in other domains such as shopping, gambling or other non-consumption indulgences. Indulgent consumption is a real problem that occurs widely in natural settings, as rising rates of obesity and binge drinking, among other symptoms, suggest. We hope that our research, despite limitations in its generalizability to the world outside the lab can spark additional research about how consumers make and cope with indulgent choices. We believe that there is a strong need for "real world" research that focuses on how people remember and respond to their emotions over time after acts of indulgence, so as to provide additional insights into how these effects observed in the lab translate into more realistic consumption behavior. 


\section{REFERENCES}

Ainslie, George (1975), "Specious Reward: A Behavioral Theory of Impulsiveness and Impulse Control,” Psychological Bulletin, 82 (July), 463-96.

Baron, Reuben. M. and David A. Kenny (1986), “The Moderator-Mediator Distinction in Social Psychological Research: Conceptual, Strategic, and Statistical Considerations,” Journal of Personality and Social Psychology, 51 (December), 1173-82.

Baumeister, Roy F. and Todd F. Heatherton (1996), "Self-Regulation Failure: An Overview,” Psychological Inquiry, 7 (January), 1-15.

Canli, Turhan, Zuo Zhao, John E. Desmond, Eunjoo Kang, James Gross, and John D.E. Gabrieli (2001), “An fMRI Study of Personality Influences on Brain Reactivity to Emotional Stimuli,” Behavioral Neuroscience, 115 (February), 33-42.

Chartrand, Tanya L. and John A. Bargh (1996), “Automatic Activation of Impression Formation and Memorization Goals: Nonconscious Goal Priming Reproduces Effects of Explicit Task Instructions,” Journal of Personality and Social Psychology, 71 (September), 464-78.

Cloninger, Robert C., Thomas R. Przybeck, and Dragan M. Svrakic (1991), “The Tridimensional Personality Questionnaire: U.S. Normative Data,” Psychological Reports, 69 (December), 1047-57.

Costa, Paul T. and Robert R. McCrae (1980), “Influence of Extraversion and Neuroticism on Subjective Well-Being: Happy and Unhappy People,” Journal of Personality and Social Psychology, 38 (April), 668-78. 
Dhar, Ravi and Itamar Simonson (1999), "Making Complementary Choices in Consumption Episodes: Highlighting versus Balancing,” Journal of Marketing Research, 36 (February), 29-44.

Diener, Ed and Randy J. Larsen (1984), “Temporal Stability and Cross-Situational Consistency of Affective, Behavioral and Cognitive Responses,” Journal of Personality and Social Psychology, 47 (April), 871-83.

Eid, Michael and Ed Diener (1999), "Intraindividual Variability in Affect: Reliability, Validity and Personality Correlates,” Journal of Personality and Social Psychology, 76 (April), 66276.

Flegal, Katherine M., Margaret D. Carroll, Cynthia L. Ogden, and Clifford L. Johnson (2002), “Prevalence and Trends in Obesity among US Adults, 1999-2000," Journal of the American Medical Association, 288 (Oct. 9), 1723-27.

Futrelle, David, (2006), “When Smart Shoppers Buy Dumb Things,” Money, 35 (January), p. 27 Gilovich, Thomas and Victoria H. Medvec (1994), "The Temporal Pattern to the Experience of Regret,” Journal of Personality and Social Psychology, 67 (September), 357-65.

Giner-Sorolla, Roger (2001), “Guilty Pleasures and Grim Necessities: Affective Attitudes in Dilemmas of Self-Control,” Journal of Personality and Social Psychology, 80 (February), 206-21.

Gray, Jeffrey A. (1987), “Perspectives on Anxiety and Impulsivity - A Commentary,” Journal of Research in Personality, 21 (December), 493-509.

Hoch, Stephen J. and George F. Loewenstein (1991), “Time-Inconsistent Preferences and Consumer Self-Control,” Journal of Consumer Research, 17 (March), 492-507. 
Kahneman, Daniel and Amos Tversky (1982), “The Simulation Heuristic” in Judgment Under Uncertainty: Heuristics and Biases, ed. Daniel Kahneman et al., New York: Cambridge, 201-08.

Kivetz, Ran and Anat Keinan (2005), “Repenting Hyperopia: Affective Antecedents and Behavioral Consequences of Self-Control Regrets,” Unpublished Working Paper.

Larsen, Jeff T., Peter McGraw, and John T. Cacioppo (2001), “Can People Feel Happy and Sad at the Same Time?” Journal of Personality and Social Psychology, 81 (October), 681-96.

Lazarus, Richard S. (1996), Emotion and Adaptation, New York: Oxford University Press.

LeDoux, Joseph (1996), The Emotional Brain: The Mysterious Underpinnings of Emotional Life, New York, NY: Touchstone

Levav, Jonathan and Peter McGraw (2004), “Emotional Accounting: Feelings about Money and Consumer Choice,” Unpublished Working Paper.

Luce, Mary Frances (1998), “Choosing to Avoid: Coping with Negative Emotion-Laden Consumer Decisions," Journal of Consumer Research, 24 (March), 409-33.

Moskowitz, Gordon B, Peter M. Gollwitzer, Wolfgang Wasel, and Bernd Schaal (1999), "Preconscious Control of Stereotype Activation Through Chronic Egalitarian Goals," Journal of Personality \& Social Psychology, 77 (July), 167-84.

Pham, Michel, Joel B. Cohen, John W. Pracejus, and G. David Hughes (2001), “Affect Monitoring and the Primacy of Feelings in Judgment,” Journal of Consumer Research, 28 (September), 167-88.

Prelec, Drazen and George F. Loewenstein (1991), “Decision-Making Over Time and Under Uncertainty: A Common Approach,” Management Science, 37 (July), 770-86. 
Priester, Joseph R. and Richard E. Petty (2001), “Extending the Bases of Subjective Attitudinal Ambivalence: Interpersonal and Intrapersonal Antecedents of Evaluative Tension,” Journal of Personality and Social Psychology, 80 (January), 19-34.

Puri, Radhika (1996), “Measuring and Modifying Consumer Impulsiveness: A Cost-Benefit Accessibility Framework,” Journal of Consumer Psychology, 5 (2), 87-113.

Ramanathan, Suresh and Geeta Menon (forthcoming), “Time-Varying Effects of Chronic Hedonic Goals on Impulsive Behavior,” Journal of Marketing Research.

Rook, Dennis W. (1987), “The Buying Impulse,” Journal of Consumer Research, 14 (September), 189-99.

Rook, Dennis W. and Robert J. Fisher (1995), “Normative Influences on Compulsive Buying Behavior,” Journal of Consumer Research, 22 (December), 305-13.

Shiv, Baba and Alexander Fedorikhin (1999), “Heart and Mind in Conflict: The Interplay of Affect and Cognition in Consumer Decision Making,” Journal of Consumer Research, 26 (December), 278-92.

Strahilevitz, Michal (1999), “The Effects of Product Type and Donation Magnitude on Willingness to Pay More for a Charity-Linked Brand,” Journal of Consumer Psychology, 8 (3), 214-41.

Tetlock, Philip E., Orie V. Kristel, Beth S. Elson, Melanie C. Green, and Jennifer S. Lerner (2000), “The Psychology of the Unthinkable: Taboo Trade-Offs, Forbidden Base Rates and Heretical Counterfactuals,” Journal of Personality and Social Psychology, 78 (May), 853-70.

Thaler, Richard H. and Hersh M. Shefrin (1981), “An Economic Theory of Self-Control,” The Journal of Political Economy, 89 (April), 392-406. 
Thompson, Megan M., Mark P. Zanna, and Dale W. Griffin (1995), “Let’s Not Be Indifferent About (Attitudinal) Ambivalence," in Attitude Strength: Antecedents and Consequences, ed. Richard E. Petty and Jon A. Krosnick, Mahwah, NJ: Erlbaum, 361-86.

Tsiros, Michael and Vikas Mittal (2000), "Regret: A Model of its Antecedents and Consequences in Consumer Decision Making,” Journal of Consumer Research, 26 (March), 401-17.

Updegraff, John, Shelly L. Gable, and Shelley E. Taylor (2004), “What Makes Experiences Satisfying? The Interaction of Approach-Avoidance Motivations and Emotions in WellBeing,” Journal of Personality and Social Psychology, 86 (March), 496-504.

Vohs, Kathleen D. and Todd F. Heatherton (2000), “Self-Regulatory Failure: A Resource Depletion Approach,” Psychological Science, 11 (March), 249-54.

Weschler, Henry, Jae Eun Lee, Meichun Kuo, Mark Seibring, Toben F. Nelson, and Hang Lee (2002), “Trends in College Binge Drinking During a Period of Increased Prevention Efforts. Findings from 4 Harvard School of Public Health College Alcohol Study Surveys: 19932001,” Journal of American College Health, 50 (5), 203-17.

Williams, Patti and Jennifer L. Aaker (2002), “Can Mixed Emotions Peacefully Co-exist?” Journal of Consumer Research, 28 (March), 636-49.

Wood, Wendy, Jeffery M. Quinn, and Deborah A. Kashy (2002), “Habits in Everyday Life: Thought Emotion and action,” Journal of Personality and Social Psychology, 83 (December), 1281-97. 
TABLE 1

PREDICTED EMOTIONAL REACTIONS AND SUBSEQUENT CHOICES

\begin{tabular}{|c|c|c|c|c|}
\hline & \multicolumn{2}{|c|}{ Impulsive Consumers } & \multicolumn{2}{|c|}{ Prudent Consumers } \\
\hline & Immediate & Delayed & Immediate & Delayed \\
\hline Positive Hedonic Emotions & High & High & High & Low \\
\hline Negative Hedonic Emotions & High & Low & High & High \\
\hline $\begin{array}{l}\text { Positive Self-Conscious } \\
\text { Emotions }\end{array}$ & Low & Low & Low & Low \\
\hline $\begin{array}{l}\text { Negative Self-Conscious } \\
\text { Emotions }\end{array}$ & Low & High & High & High \\
\hline $\begin{array}{l}\text { E1: Likelihood to Make } \\
\text { Second Indulgent Choice }\end{array}$ & High & High & Low & Low \\
\hline $\begin{array}{l}\text { E2: Likelihood to Launder } \\
\text { Negative Emotions }\end{array}$ & & & & \\
\hline
\end{tabular}


TABLE 2

EXPERIMENT 1 RESULTS

\begin{tabular}{lcccc} 
& \multicolumn{2}{c}{ Impulsive Consumers } & \multicolumn{2}{c}{ Prudent Consumers } \\
& Immediate & Delayed & Immediate & Delayed \\
\hline \hline $\begin{array}{l}\text { Positive Hedonic Emotions } \\
\text { Negative Hedonic Emotions }\end{array}$ & 4.96 & 4.42 & 4.86 & 2.23 \\
$\begin{array}{l}\text { Positive Self-Conscious } \\
\text { Emotions }\end{array}$ & 2.84 & 2.09 & 5.14 & 5.21 \\
$\begin{array}{l}\text { Negative Self-Conscious } \\
\text { Emotions }\end{array}$ & 1.63 & 2.93 & 2.51 & 3.00 \\
$\begin{array}{l}\text { Likelihood to Make Second } \\
\text { Choice }\end{array}$ & 5.40 & 2.89 & 5.17 & 5.61 \\
& & & & \\
\end{tabular}


TABLE 3

EXPERIMENT 2 RESULTS

\begin{tabular}{|c|c|c|c|c|c|c|c|c|}
\hline \multirow{3}{*}{$\begin{array}{c}\text { Type of Second } \\
\text { Choice }\end{array}$} & \multicolumn{4}{|c|}{ Impulsive Consumers } & \multicolumn{4}{|c|}{ Prudent Consumers } \\
\hline & \multicolumn{2}{|c|}{ Hedonic } & \multicolumn{2}{|c|}{ Utilitarian } & \multicolumn{2}{|c|}{ Hedonic } & \multicolumn{2}{|c|}{ Utilitarian } \\
\hline & Time 1 & Time 2 & Time 1 & Time 2 & Time 1 & Time 2 & Time 1 & Time 2 \\
\hline $\begin{array}{l}\text { Positive Hedonic } \\
\text { Emotions }\end{array}$ & 5.19 & 5.04 & 4.75 & 4.73 & 5.14 & 4.85 & 5.17 & 4.70 \\
\hline $\begin{array}{l}\text { Negative } \\
\text { Hedonic } \\
\text { Emotions }\end{array}$ & 4.77 & 5.72 & 4.43 & 4.41 & 4.76 & 5.18 & 4.60 & 1.45 \\
\hline $\begin{array}{l}\text { Positive Self- } \\
\text { Conscious } \\
\text { Emotions }\end{array}$ & 1.53 & 1.51 & 1.50 & 1.53 & 2.06 & 2.02 & 2.00 & 2.28 \\
\hline $\begin{array}{l}\text { Negative Self- } \\
\text { Conscious } \\
\text { Emotions }\end{array}$ & 1.85 & 1.78 & 2.22 & 2.64 & 5.21 & 4.97 & 5.10 & 1.40 \\
\hline $\begin{array}{l}\text { Percentage } \\
\text { Making Second } \\
\text { Choice }\end{array}$ & & & & & & & & \\
\hline
\end{tabular}


Headings List

\section{THE EMOTIONAL CONSEQUENCES OF INDULGENCE}

2. The Accessibility of Hedonic and Self-conscious Emotions Immediately and Over Time

3. Immediate Consequences of Indulgence

3. Delayed Emotional Consequences of Indulgence

2. The Impact of Indulgence-Related Emotions on Subsequent Choice

2. Undoing Ambivalence: Laundering Negative Emotions

\section{EXPERIMENT 1}

2. Method

3. Participants and Procedure

2. Results

3. Impulsivity versus Prudence

3. Indulgent Cookie Choice

3. Emotional Responses to Indulgence

3. Hedonic Emotional Responses to Indulgence

3. Self-Conscious Emotional Responses to Indulgence

3. Likelihood to Indulge a Second Time

3. Mediation

2. Discussion

1. EXPERIMENT 2

2. Method

3. Participants and Procedure

2. Results

3. Impulsivity versus Prudence

3. Indulgent Cookie Choice

3. Chips or Notepad Choice

3. Hedonic Emotional Responses to Indulgence

3. Self-Conscious Emotional Responses to Indulgence

3. Mediation

2. Discussion

1. GENERAL DISCUSSION

\section{REFERENCES}

